\title{
Reverse Innovation: Create Far From Home, Win Everywhere
}

\author{
Book Review
}

\author{
Author: Vijay Govindrajan, Chris Trimble \\ Reviewed by: Shiva Kumar Srinivasan \\ Behavioral Sciences, IIPM Chennai, India \\ sksrinivasan2008@hotmail.com
}

What is reverse innovation? And why should it matter to strategic theorists? What furthermore are the practical applications and relevant instances of reverse innovation? These are the three important questions that Vijay Govindrajan and Chris Trimble of the Tuck School of Business, Dartmouth College take up in this engaging book. This is the third volume in a trilogy of books on the theory and practice of innovation that they have 'co-created' in the last few years with a specific focus on 'global strategy and innovation'. This book, incidentally, is dedicated to the late C. K. Prahalad - whom they endearingly refer to as a 'guiding light' - given his pioneering work in the area of strategic innovation. Govindrajan and Trimble situate their work as belonging to the 'strategy as innovation' school of thought, but reverse the direction of innovation: it flows surprisingly enough in their understanding from emerging markets to the West. This notion of 'reversals' is cognitively linked to the 'reversal of fortune' plot structure that Western writers are fond of and is not specific to strategic theory and practice. Larry Summers, for instance, is fond of delineating reversals in the flows of capital from emerging economies to the West not only in the wake of the economic crisis of 2008,but also because of the rising strategic importance of 'sovereign wealth funds' for re-capitalizing Western firms. Likewise, strategic product development, as Govindrajan and Trimble argue, is subject to a reversal in direction.

Emerging economies not only provide the locus for strategic innovation in the sense of being able to better address the idiosyncratic needs of their economies, but are also more likely to be in a position to meet the needs of those segments of Western markets that bear a resemblance to these economies. A number of such instances have already been discussed and written up by strategists and a number of cases and case-based examples can be found in this book as well. It would not be an exaggeration to say that the re-vitalization of case writing in strategy is going to proceed in this direction in the near future. The work of Govindrajan and Trimble represents both cause-and-effect in the sense in which their attempts at an academic 'formalization' of this area is coeval with the emergence of this area as a problem of consequence in the global economy. As proof of the growing realization of the importance of reverse innovation amongst multinationals, readers have to but consider the remarks made by Indra Nooyi of Pepsico in the foreword to this book, where she directly correlates her firm's strategic approaches to reverse innovation with the over-all thrust of the argument here. Nooyi identifies three important takeaways in terms of how cultural similarities and differences affect what and how people consume, and how Pepsico was able to leverage on the range of strategic insights available in studies like this in developing its range of healthy snacks. She argues that familiarity with this literature can prevent firms seeking to reverse innovate from going astray given their lack of familiarity with product development in the emerging economies.

There are two parts to this book: the first sets out the 'challenges' of reverse innovation while the second is a collection of eight cases on reverse innovation comprising firms like Logitech, P\&G, EMC Corporation, Deere \& Co, Harman, GE Healthcare, Pepsico, and Partners in Health. This section of cases concludes with the 'do's and don'ts' of reverse innovation and two appendices that not only set out 'a reverse innovation toolkit' but also spell-out a 'research agenda' for those who would like to move further in this direction. This agenda is not only for business academics but also for firms that would like to take up this challenge on the field. The cases cover the reverse innovation challenge in a number of sectors as though to say that it is not specific to any given sector, but represents an entirely new way of looking at product innovation and development. Govindrajan and Trimble identify not only the challenges, but the specific forms of constraints that must be overcome in order to innovate or to at least design around in order to commercialize these reverse innovations successfully. Govindrajan and Trimble also argue that the absence of adequate physical, social, and institutional infrastructure demands a change in the cognitive patterns that constitute the effective preconditions for reverse innovation. 
Govindrajan and Trimble also point out that the markets for reverse innovation are not reducible to the emerging economies, but can be identified in the advanced economies as well. In fact, it does not make much sense in invoking such traditional analytic distinctions since a revised notion of market segmentation is required to identify the target audience for reverse innovations. Just as the notion of purchasing power parity changes dramatically what is understood to be the consumer's ability to pay while comparing economies; so, likewise, we have to segment across rather than segment within markets that can be conveniently termed 'advanced' or 'emerging'. What is needed here then is not an attribute analysis of products developed under the aegis of reverse innovation per se; but, more importantly, an understanding of the circumstances, challenges, and constraints that warrant the development and deployment of such products. Reverse innovation then is necessarily related to global markets and a much more open notion of market segmentation than was previously the case. That is probably why the role of C. K Prahalad as a predecessor in formulating such theories is important given that his notion of the bottom of the pyramid is at the locus of convergence between strategy and marketing. While it is not the case that all reverse innovations are aimed at the 'bottom of the market' - Govindrajan and Trimble cite examples of the 'middle of the pyramid' as well - it is a lot easier for them to innovate within strategic theory given that the quest for alternative markets that deconstructs the advanced markets/emerging markets opposition is a fait accompli from Prahalad's work saving theorists of reverse innovation a lot of unnecessary trouble. What is needed however is a greater sensitization of the mind-set needed to make reverse innovation a way of life for firms in the years to come. This lucid book by Govindrajan and Trimble is a major contribution in that direction. 